\title{
Six Clinical Predictors for Intractable Childhood Epilepsy
}

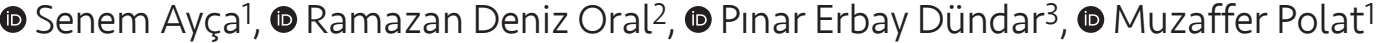 \\ ${ }^{1}$ Celal Bayar University Faculty of Medicine, Department of Pediatric Neurology, Manisa, Turkey \\ ${ }^{2}$ Celal Bayar University Faculty of Medicine, Department of Pediatrics, Manisa, Turkey \\ ${ }^{3}$ Celal Bayar University Faculty of Medicine, Department of Public Health, Manisa, Turkey
}

\begin{abstract}
Aim: This study aimed to determine the significance of six clinical predictors associated with medically intractable childhood epilepsy.

Materials and Methods: A retrospective cohort study was conducted. A total of 241 children with diagnosed epilepsy were recruited and divided into two groups: 61 patients with intractable epilepsy, and the other 180 patients who responded well to antiepileptic drugs. We investigated seizure semiology, etiology of epileptic encephalopathy, EEG abnormalities and defined the odds ratios (ORs) of predictor factors for intractable childhood epilepsy; age of seizure onset, asphyxia, neonatal intensive care unit (NICU) history, consanguineous marriage, abnormal neuro-imaging, neuropathologic exam, prematurity, parents' seizure history.

Results: According to logistic regression analysis, the major risk factors for intractable childhood epilepsy are (1) neuropathologic examination $p=0.000, O R=58.28 \mathrm{Cl}=23.95-141.63 ;(2)$ abnormal neuro-imaging $p=0.000, O R=37.55 \mathrm{Cl}=16.41-85.94$ (3) age of seizure onset $p=0.001, O R=$ 9.43 confidence interval $(\mathrm{Cl}): 3.66-24.3(4)$ asphyxia $p=0.001 \mathrm{OR}=4.16 \mathrm{Cl}=1.75-9.87(5)$ consanguineous marriage $p=0.001 \mathrm{OR}=3.02 \mathrm{Cl}=1.53-$ 5.97 (6) NICU history $\mathrm{p}=0.003 \mathrm{OR}=2.59 \mathrm{Cl}=1.38-4.87(95 \% \mathrm{Cl})$.

Conclusion: The presented six predictors can be used to determine the medical intractability in children with epilepsy in order to provide early alternative treatment protocols for better seizure control.

Keywords: Childhood epilepsy, intractability, epileptic encephalopathy, predictor factors
\end{abstract}

\section{Introduction}

Epilepsy is a heterogeneous group of neurological diseases characterized by recurrent non-triggered seizures (1). Although the condition often responds well to single drug therapy, in some cases, seizure control cannot be achieved by two or more drugs. This group is defined as resistant epilepsy, which accounts for 30\%-35\% of all epilepsies. The concept of resistant epilepsy was defined by the International League Against Epilepsy (ILAE) in 2010 as the failure to achieve seizure freedom in a period of three months and having on average one seizure per month, despite adequate trials of two or more tolerated, appropriately chosen and used anti-epileptic drugs (whether as mono-therapies or in combination) with effective serum levels (2).

Early detection of resistant epileptic patients may be possible with the identification of predisposing factors. Anatomical and functional connections in developing brains are different from mature brains, assynaptic structuring and modification continue and plasticity is seen in a higher 
ratio (3). Seizure control via early treatment in childhood epilepsies has significant importance for the prevention of neuronal damage due to recurrent seizures, attaining normal development, minimizing drug side effects and increasing quality of life (4). The aim of this study was to determine the leading factors for resistant epilepsy in epileptic patients presenting at Manisa Celal Bayar University Faculty of Medicine, Department of Pediatric Neurology.

\section{Materials and Methods}

This retrospective study was conducted as a case control type at Celal Bayar University Medical Faculty Pediatric Neurology Clinic between 01/01/2011-31/12/2015. The charts of 2.200 patients who presented due to seizures were examined. Patients having two or more non-triggered seizures on different days were diagnosed with epilepsy. The patient group consisted of 61 intractable epilepsy patients who were followed regularly for at least two years. Power analysis was performed according to sample size and determined as $90 \%$ when $d=0.60, \alpha=0.05$ was accepted (5).

The control group consisted of 180 cases selected by a simple random sampling method among epileptic patients who responded well to antiepileptic drugs, matched with age and gender. Age and gender, first seizure age, seizure features, asphyxia, premature birth, hospitalization in neonatal intensive care unit, consanguineous marriage, parents' seizure history and neurological examination findings were recorded from both group charts.

The first electroencephalographic (EEG) findings of the patients were reviewed by the same pediatric neurologist. These were divided into two groups: normal and abnormal EEG. Abnormal EEG findings were listed as focal/multifocal pattern, organizational impairment/slow pattern, generalized disorders and specific disorders (burst suppression, hypsarrhythmia etc.). Likewise, initial magnetic resonance imaging (MRI) results were classified as normal and abnormal [the findings revealed acquired conditions (trauma, stroke, infection), structural and congenital anomalies, neurometabolic and neurodegenerative disease].

The study was approved by the Celal Bayar University Medical Faculty Local Ethics Committee (approval number: 20478486-296, date: 19,08,2015). Consent form was filled out by all participants.

\section{Inclusion and Exclusion Criteria}

Selection of the Patient Group: Epileptic patients without a seizure-free period of three months and having on average one seizure per month despite adequate trials of two or more tolerated, appropriately chosen and used antiepileptic drugs (whether as mono-therapies or in combination) with effective serum levels were considered as resistant epileptic patients. Among these intractable epileptic patients, 61 were included in this study. Medications used at the time of seizure in the emergency room and during epileptic status, medications discontinued without effect or due to side effects were not included in the used drug list of cases.

Selection of the control group: The control group consisted of 180 patients who responded well to antiepileptic drugs alone or two in combination.

\section{Definitions}

The classification and terminology of the ILAE was used for this study. Classification of seizure type was made according to revised International Classification of Epileptic Seizure. Videos of the first seizure recorded in hospital (if available) were used to classify the seizures. Otherwise, the classification was made based mainly on information received from family members who saw the seizure.

Asphyxia was defined as having an Apgar score below 3 in the first minute, below 5 in the fifth minute, an interventional birth, difficult (traumatic) birth, late crying and late onset of respiration or the need for resuscitation at birth. Patients whose records were unclear concerning these data were not included in this study. The reason for the neonatal hospital admission (difficult birth, premature birth, newborn infection, jaundice) was investigated. Motor mental retardation was evaluated in consideration with the delay in the developmental stages and/or developmental tests (Denver or WISCR-R) made according to age groups. Presence of decreased muscle strength, tonus changes, deep tendon reflexes, pathological reflexes, involuntary movements, disturbance in walking and posture, defect in balance and sense examination were considered in pathologic neurological examination. Neurocutaneous diseases, diagnosed or suspected by physical examination revealing signs such as café au lait spots, hypopigmented skin findings, were noted. The pathologies identified in electroencephalography were classified as generalized sharp and/or spike waves, focal-multifocal sharp waves, ground rhythm disturbances (deficiency in backward maturation, asymmetry etc.) and specific disorders (burst suppression, hypsarrhythmia etc.). Cranial imaging findings were divided into either with pathology or without pathology. 


\section{Statistical Analysis}

The SPSS 15.0 programme was used for the statistical analysis of the study. Chi-square tests were used to compare differences between categorical variable frequencies and Student's t-tests were used to compare continuous variables in two independent groups. Risk analysis of the independent variables was also performed in the case and control group. Estimated relative risks were presented as the OR and 95\% $\mathrm{Cl}$. The level of statistical significance was set at $p<0.05$.

\section{Results}

\section{General Features}

A total of 241 patients consisting of intractable epilepsy (61) and drug-responsive epilepsy (180) were included in the study. There were 111 females (46.1\%) and 130 males (53.9\%). Among the 61 intractable cases, 35 were male $(57.4 \%)$ and 26 were female (42.6\%). Ninety-five males (52.8\%) and 85 females (47.2\%) were in the drug-responsive epileptic group. There was no statistically significant difference between the groups in terms of gender $(p=0.318)$. The mean age of the intractable epilepsy group was $7.00 \pm 4.36$ years and the mean age of the control group was $7.18 \pm 4.51$ years $(p=0.795)$. There was no statistically significant difference between the groups. It was seen that the age of first seizure was mostly in the $0-1$ age range (65.6\%) in the intractable epilepsy group, whereas the range was found mostly in the $1-5$ years $(45.0 \%)$ in the drug-responsive epilepsy group. This showed that as the age increased, the frequency of intractable epilepsy decreased and this relationship was significant $(p=0.001)$.

When the risk factors for intractable epilepsy were evaluated in both groups, the presence of neuropathologic examination, asphyxia history, consanguineous marriage, neonatal intensive care unit (NICU) history and abnormal neuro-imaging findings and age of seizure onset being less than 1 year were statistically significant. The presence of pathological examination findings was the most important risk factor of the intractable childhood epilepsy ( $p=0.000$; $\mathrm{OR}=58.26 ; 95 \% \mathrm{Cl}=23.97-141.63)$. Abnormal imaging, the asphyxia history, consanguineous marriage and NICU admission were significantly higher in the intractable epilepsy group. However, the parents' history for epilepsy $(p=0.057 ; O R=1.71 ; 95 \% \mathrm{Cl}=0.93-3.12)$ and prematurity $(p=0.353 ; O R=1.24 ; 95 \% \mathrm{Cl}=0.57-2.69)$ were not significant risk factors (Table I).

The most common type of seizures was partial type (42.6\%), generalized tonic-clonic (24.6\%) and myoclonic seizures $(14.8 \%)$ in the intractable epilepsy group. Epileptic spasms were seen only in the intractable epilepsy group, at a rate of $8.2 \%$. In the drug-responsive epilepsy group, the most common type of seizures was generalized tonic-clonic (31.6\%), partial type (23.8\%) and generalized tonic (17.8\%) (Table II).

While the first-line EEG findings were pathologic in all intractable epilepsy cases, the pathologic EEG results were $54.3 \%$ in the drug-responsive epilepsy group. In a separate evaluation of the results of patients having pathologic EEG, the most common EEG pathology in both groups was a focal/multifocal epileptiform pattern. The second most common pathology was the generalized epileptiform pattern. A statistically significant difference was found between the case and control groups in terms of EEC pathologies (Table III).

\section{Classification of Epileptic Encephalopathy}

Of the 61 patients in the intractable epilepsy group, $28(45.9 \%)$ were found to have epileptic encephalopathy. West syndrome in $12(42.8 \%)$ cases was the most common among these cases with epileptic encephalopathy. The second most common type was electrical status epilepticus of sleep syndrome in $5(17.8 \%)$ patients. The number of cases with Lennox-Gestaut syndrome was 4 (14.2\%), cases with Dravet syndrome were $3(10.8 \%)$, cases with LandauKleffner syndrome were $2(7.2 \%)$ and there were 2 (7.2\%) cases with Doose syndrome.

\section{Discussion}

Approximately 30\%-35\% of childhood epilepsies are intractable epilepsies (2). Various medical problems including aspiration, cardiac arrhythmia or refractory status epilepticus are frequently observed in patients with intractable epilepsy. In particular, children are more susceptible to drug toxicity due to multiple drug use and behavioral and academic problems are more likely to develop.

Factors that may lead to resistance development in childhood are not clear and are thought to be multifactorial. One of the notable risk factors is age at onset of seizures. In many studies based on age at onset of the first seizure, the ratios of seizure in the first year of life ranged from $50 \%$ to $60 \%$ in intractable epilepsy patients and from $10 \%$ to $20 \%$ in drug-responsive epilepsy patients, and this was reported as a risk factor (6-8). It is known that the onset of seizures within the first year of life facilitates the epileptogenic tendency during the development of the immature brain (9). In this study, we found that the $65.6 \%$ of patients with intractable epilepsy had their first seizure at under one year of age, in line with other studies ( $p=0.001)$. 
It is known that having neonatal seizures in premature infants and abnormal brain MRI results are associated with poor prognosis in terms of neurological development (10). Pathologic cranial MRI has been found in all premature infants who had seizures due to various reasons during the neonatal period and progressed to resistant epilepsy $(11,12)$. In this study, although the presence of prematurity was not significant in terms of risk of resistant epilepsy $(p=0.353)$, cranial MRI findings were pathologic in all four patients with resistant epilepsy and premature birth.

It has been reported that epilepsy seen in neonatal intensive care units due to various reasons was a risk factor for intractability and an important etiological cause.
Gururaj et al. (13) showed that $18 \%$ of patients in a neonatal intensive care unit had their first seizure and a significant relationship was found between them in terms of resistance development. Hypoxic or asphyxic events, seen especially in the perinatal period, facilitate epileptogenesis in the future and are important in the development of resistance by leading epileptic foci (14). Hypoxic ischaemic encephalopathy (HIE) is one of the most important causes of mortality and morbidity in the neonatal period. In a study conducted in our country, it was reported that HIE is associated with a mortality rate of $10 \%-50 \%$ and morbidity rate of $21 \%-55 \%$ in the advanced stage (15). In another study, Gürbüz et al. (16) found

Table I. The predictor risk factors for intractable childhood epilepsy according to logistic regression analysis

\begin{tabular}{|c|c|c|c|c|c|c|}
\hline \multirow{2}{*}{ Variables } & \multicolumn{2}{|c|}{ Intractable epilepsy } & \multicolumn{2}{|c|}{ Drug responsive epilepsy } & \multirow{2}{*}{$p$ value } & \multirow{2}{*}{ OR (95 Cl\%) } \\
\hline & Number & $\%$ & Number & $\%$ & & \\
\hline \multicolumn{7}{|l|}{ Age of seizure onset } \\
\hline $0-1$ & 40 & 65.6 & 41 & 22.8 & \multirow{3}{*}{0.001} & $9.43(3.66-24.30)$ \\
\hline $1-4$ & 15 & 24.6 & 81 & 45.0 & & $1.79(0.65-4.89)$ \\
\hline 5 years and above (ref) & 6 & 9.8 & 58 & 32.3 & & $1.04(0.11-9.91)$ \\
\hline \multicolumn{7}{|l|}{ Prematurity } \\
\hline Yes & 11 & 18 & 27 & 15 & \multirow{2}{*}{0.353} & \multirow{2}{*}{$1.24(0.57-2.69)$} \\
\hline No (ref) & 50 & 82 & 153 & 85 & & \\
\hline \multicolumn{7}{|l|}{ Asphyxia } \\
\hline Yes & 13 & 21 & 11 & 6.1 & \multirow{2}{*}{0.01} & \multirow{2}{*}{$4.16(1.75-9.87)$} \\
\hline No (ref) & 48 & 78 & 169 & 93.9 & & \\
\hline \multicolumn{7}{|l|}{ NICU history } \\
\hline Yes & 24 & 39.7 & 36 & 20 & \multirow{2}{*}{0.003} & \multirow{2}{*}{$2.59(1.38-4.87)$} \\
\hline No (ref) & 37 & 60.3 & 144 & 80 & & \\
\hline \multicolumn{7}{|l|}{ Parents seizure history } \\
\hline Yes & 25 & 41 & 52 & 28.9 & \multirow{2}{*}{0.057} & \multirow{2}{*}{$1.71(0.93-3.12)$} \\
\hline No (ref) & 36 & 60.7 & 128 & 71.1 & & \\
\hline \multicolumn{7}{|c|}{ Consanguineous marriage } \\
\hline Yes & 20 & 32.8 & 25 & 13,9 & \multirow{2}{*}{0.001} & \multirow{2}{*}{$3.02(1.53-5.97)$} \\
\hline No (ref) & 41 & 67.2 & 155 & 86.1 & & \\
\hline \multicolumn{7}{|l|}{ Abnormal imaging } \\
\hline Yes & 38 & 85.2 & 11 & 13.3 & \multirow{2}{*}{0.000} & \multirow{2}{*}{$37.55(16.41-85.94)$} \\
\hline No (ref) & 23 & 14.8 & 169 & 86.7 & & \\
\hline \multicolumn{7}{|l|}{ Neuropathologic exam } \\
\hline Yes & 46 & 75.4 & 9 & 5 & \multirow{2}{*}{0.000} & \multirow{2}{*}{$58.26(23.95-141.63$} \\
\hline No (ref) & 15 & 24.6 & 171 & 95 & & \\
\hline Totally & 61 & 100 & 180 & 100.0 & - & - \\
\hline
\end{tabular}

OR: Odds ratio, Cl: Confidence interval, NICU: Neonatal intensive care unit 
that risk factors that have influence on the prognosis of patients with neonatal seizures are etiological diagnosis, seizure type, birth weight, abnormal EEG activity and status epilepticus. In our study, the presence of neonatal intensive care admission history increased the risk of intractable epilepsy by 2.59 (95\% Cl= 1.38-4.87) times and increased the intractability development rate by 4.16 (95\% Cl= 1.75-9.87) times, especially if admitted due to asphyxiated delivery.

Another criterion that has been the subject of many studies as a risk factor for the development of intractability in epileptic patients is the first seizure type. Gururaj et al. (13) and Chawla et al. (14) found the generalized tonic seizure was the most common type in the intractable epilepsy group in their case control studies. On the other hand, Ohtsuka et al. (17) reported myoclonic as the most common, while Kwong et al. (18) reported that partial seizure was seen most. In our study, the most common seizure type was partial seizure in the intractable epilepsy group. The cause of the variation of seizure type frequencies reported so widely in different studies is directly related to observation of the seizure moment for the first time by the mother and other relatives and unclear definition or limited experience of the first-seen or referred to physician.

The presence of various pathologies in the neurological examination in epileptic patients is thought to be associated with the development of intractable epilepsy. In a few studies from Chawla et al. (14) and Seker Yilmaz et al. (19), the pathologic-neurological examination was found to be significant and high in intractable epilepsy cases. In accordance with the literature, in our study, the presence of pathologic findings on neurological examination was found to be 58 times more in intractable epilepsy and has been shown as the most important risk factor $(p=0.000$; $\mathrm{OR}=58.26 ; 95 \% \mathrm{Cl}=23.95-141.63)$. This possibly reflects the severity of brain damage.

In our study, positive family seizure history did not seem to pose a risk for the development of intractable epilepsy. Similarly, in one study, there was no significant correlation found between family history and intractable epilepsy (20).

Table II. Distribution of both groups according to seizure semiology

\begin{tabular}{|c|c|c|c|c|c|c|c|}
\hline & \multicolumn{2}{|c|}{ Intractable epilepsy } & \multicolumn{2}{|c|}{$\begin{array}{l}\text { Drug responsive } \\
\text { epilepsy }\end{array}$} & \multicolumn{2}{|l|}{ Total } & \multirow[t]{2}{*}{$p$ value } \\
\hline & Number & $\%$ & Number & $\%$ & Number & $\%$ & \\
\hline Generalized tonic & 4 & 6.6 & 32 & 17.8 & 36 & 14.8 & \multirow{8}{*}{0.000} \\
\hline Generalized tonic clonic & 15 & 24.6 & 57 & 31.6 & 72 & 29.8 & \\
\hline Myoclonic & 9 & 14.8 & 12 & 6.6 & 21 & 8.6 & \\
\hline Atonic & 1 & 1.6 & 24 & 13.4 & 25 & 10.4 & \\
\hline Epileptic spasm & 5 & 8.2 & 0 & 0 & 5 & 2.2 & \\
\hline Partial seizure & 26 & 42.6 & 43 & 23.8 & 69 & 28.6 & \\
\hline Absence & 1 & 1.6 & 12 & 6.6 & 13 & 5.4 & \\
\hline Total & 61 & 100 & 180 & 100 & 241 & 100 & \\
\hline
\end{tabular}

Table III. Distribution of both groups according to electroencephalographic findings

\begin{tabular}{|l|l|l|l|l|l|l|l|}
\hline \multirow{2}{*}{} & \multicolumn{2}{|l|}{ Intractable epilepsy } & \multicolumn{2}{l|}{$\begin{array}{l}\text { Drug responsive } \\
\text { epilepsy }\end{array}$} & \multicolumn{2}{l|}{ Total } \\
\cline { 2 - 8 } & Number & $\%$ & Number & $\%$ & Number & $\%$ \\
\hline Focal / multifocal pattern & 23 & 37.7 & 47 & 26.1 & 70 & 29.0 \\
\hline Organization disorders /slow pattern & 12 & 19.7 & 16 & 8.9 & 28 & 11.6 \\
\hline Generalized disorders & 17 & 27.9 & 33 & 18.3 & 50 & 20.7 \\
\hline Burst suppression & 1 & 1.6 & 0 & 0 & 1 & 0.4 \\
\hline Hipsarrhytmia & 8 & 13.1 & 0 & 0 & 8 & 3.000 \\
\hline Normal & 0 & 0 & 84 & 46.7 & 84 & 34.9 \\
\hline Total & 61 & 100 & 180 & 100 & 241 & 100 \\
\hline
\end{tabular}


In the intractable epilepsy group, 32.8\% of the children's parents had consanguineous marriage. The consanguineous marriages were significantly higher in the intractable epilepsy group when the two groups were compared. We consider that genetic etiologies are crucial predictors for intractability. Both genetic research and family screening programs as well as future genetic studies will guide resistance development, prognosis and treatment methods.

Evaluation of the EEG findings, detection of pathological findings and classification of these findings that led to the development of more intractable epilepsy types has been another researched subject. In a study conducted by Gururaj et al. (13), there was no difference between pathological EEG results of resistance epilepsy cases and drug-responsive cases, and this was not considered as a risk factor. However, in this study, about half of the first EEG results of drug-responsive epilepsy patients were pathologic, whereas in the intractable epilepsy patient group, all of the first EEG results were found to be pathological. Berg et al. (21) reported that the focal epileptiform pattern was found to be the most common EEG abnormality in the development of refractory epilepsy. On the other hand, Ohtsuka et al. (6) found that the detection of generalized abnormalities in EEG was seen as an important factor in the development of intractable epilepsy. In our study, the focal/multifocal epileptiform pattern was the most common pathologic EEG finding in both groups and it did not lead to a prediction of the development of intractable epilepsy. However, the findings of burst suppression and hypsarrhythmia patterns, which can be seen in patients with specific epileptic encephalopathy, were found only in patients with intractable epilepsy.

When cranial MRI findings were examined, pathology was found in $62 \%$ of patients with intractable epilepsy, whereas it was only found in $18 \%$ of patients in the drugresponsive group. This demonstrates that the presence of pathologic MRI findings increases the likelihood of developing intractable epilepsy. In a study conducted by Chawla et al. (22), a strong correlation was found between the results of cranial MRI and the development of intractable epilepsy. In addition, the pattern of the pathological finding of MRI was also considered a risk factor for the development of intractable epilepsy. Russo et al. (23) conducted a study for this purpose and found structural and heterogeneous brain malformations more frequently. In our study, structural and congenital anomalies (34.6\%) were the most common pathologies found in the intractable epilepsy group.
According to the data obtained in our study, the most important predictive risk factors for intractable epilepsy in childhood epilepsies were found as onset of seizures before one year of age, asphyxia history, neonatal intensive care hospitalization and consanguineous marriage. Early factors affecting the central nervous system appear to play an important role in the development of intractability. Acceptable treatment and follow-up are especially crucial for newborns with early onset seizures and perinatal asphyxic history. When the first seizure is of the partial type, the presence of pathologic findings in cranial MRI, the presence of pathology in neurological examination and the presence of pathologic findings in EEG were found to be other risk factors.

This case control study aimed to determine the risk factors for the development of intractable epilepsy and therefore the research design in relation to the cause and potential bias sources should be considered. Prospectively conducted cohort studies and multi-center case control studies are necessary in the investigation of causality. These are the limiting aspects of our study. However, this research was designed as a case control type in a rare health problem and the $90 \%$ sampling power is a powerful aspect of this study.

\section{Conclusion}

In long-term prognosis, it is important to switch dynamically to polytherapy in the early period of treatment and to apply non-pharmacological treatment, if necessary, in those patients with predictive factors for intractable epilepsy. The present study determined the risk ratios for intractable epilepsy in a Turkish population. During follow-up, it should be carefully questioned whether these six predictor factors are met; if so, the follow-up should be more intense, caregiver and parental support should be increased and different treatment options should be considered.

\section{Ethics}

Ethics Committee Approval: The study was approved by the Celal Bayar University Medical Faculty Local Ethics Committee (approval number: 20478486-296, date: 19.08.2015).

Informed Consent: Consent form was filled out by all participants.

Peer-review: Externally peer-reviewed.

\section{Authorship Contributions}

Surgical and Medical Practices: S.A., R.D.O., Concept: M.P, Design: M.P., Data Collection or Processing: S.A., R.D.O., 
Analysis or Interpretation: S.A., P.E.D., M.P., Literature Search: S.A., R.D.O., P.E.D., Writing: S.A.

Conflict of Interest: No conflict of interest was declared by the authors.

Financial Disclosure: The authors declared that this study received no financial support.

\section{References}

1. Cowan LD. The epidemiology of the epilepsies in children. Ment Retard Dev Disabil Res Rev 2002;8:171-81.

2. Kwan P, Arzimanoglou A, Berg AT, et al. Definition of drug resistant epilepsy: Consensus proposal by the ad hoc task Force of the ILAE Commission on Therapeutic Strategies. Epilepsia 2010;51:1069-77.

3. Ramos-Lizana I, Rodriguez-Lucenilla MI, Aguilera-López P, Aguirre-Rodríguez I, Cassinello-García E. A study of drugresistant epilepsy testing the new ILAE criteria. Seizure 2012;26672.

4. Porter BE. Neurogenesis and epilepsy in the developing brain. Epilepsia 2008;49:50-4.

5. Portney LG, Watkins MP. Foundations of clinical research applications to practice. 1993; 660-1.

6. Ohtsuka Y, Yoshinaga H, Kobayashi K. Refractory childhood epilepsy and factors related to refractoriness. Epilepsia 2000;41(Suppl 9):14-7.

7. Saygı S, Erol I, Alehan F. Early clinical predictors of intractable epilepsy in childhood. Turk J Med Sci 2014;44:490-5.

8. Oskoui M, Webster RI, Zhang X, Shevell MI. Factors predictive of outcome in childhood epilepsy. I Child Neurol 2005;20:898-904.

9. Arts WF, Brouwer OF, Peters AC, et al. Course and prognosis of childhood epilepsy: 5-year follow-up of the Dutch study of epilepsy in childhood. Brain 2004;127:1774-84.

10. Ramos-Lizana J, Aguilera-López P, Aguirre-Rodríguez J, Cassinello-García E. Response to sequential treatment schedules in children epilepsy: Risk for development of refractory epilepsy. Seizure 2009;18:620-4.
11. Akçay A, Yılmaz S, Gökben S, Serdaroğlu G, Tekgül H. Neurological and developmental outcome of children with neonatal hypoglycemic seizures. Behcet Uz Cocuk Hast Dergisi 2014;4:37-43.

12. Garcias da Silva LF, Nunes ML, da Costa JC. Risk factors for developing epilepsy after neonatal seizures. Pediatr Neurol 2004;30:271-7.

13. Gururaj A, Sztriha L, Hertecant J, Eapen V. Clinical predictors of intractable childhood epilepsy. I Psychosom Res 2006;61:343-7.

14. Chawla S, Aneja S, Kashyap R, Mallika V. Etiology and clinical predictors of intractable epilepsy. Pediatr Neurol 2002;27:86-91.

15. Acunaş B, Çeltik C, Garipardıç M, Karasalihoğlu S. Perinatal asfiksili yenidoğanların etiyoloji, klinik ve prognoz açısından değerlendirilmesi. Türkiye Klinikleri J Pediatr 1999;8:21-6.

16. Gürbüz G, Ünalp A, Ünal N, Çalkavur \$̧, et al. Etiological profile of the newborns who had convulsions and evaluation of their neurodevelopmental outcomes. Behcet Uz Cocuk Hast Derg 2015;5:43-7.

17. Ohtsuka $Y$, Yoshinaga $H$, Kobayashi $K$, et al. Predictors and underlying causes of medically intractable localization-related epilepsy in childhood. Pediatr Neurol 2000;24:209-13.

18. Kwong L, Sung WY, Wong SN, So KT. Early predictors of medical intractability in childhood epilepsy. Pediatr Neurol 2003;29:4652.

19. Seker Yilmaz B, Okuyaz C, Komur M. Predictors of intractable childhood epilepsy. Pediatr Neurol 2013;48:52-5.

20. Huang L, Li S, He D, Bao W, Li L. A predictive risk model for medical intractability in epilepsy. Epilepsy Behav 2014;37:282-6.

21. Berg AT, Shinnar S, Levy SR, Testa FM, Smith-Rappaport S, Beckerman B. Early development of intractable epilepsy in children: A prospective study. Neurology 2001;56:1445-52.

22. Chawla S, Aneja S, Kashyap R, Mallika V. Etiology and Clinical Predictors of intractable epilepsy. Pediatr Neurol 2002;27:18691.

23. Russo A, Posar A, Conti S, Parmeggiani A. Prognostic factors of drug-resistant epilepsy in childhood: An Italian study. Pediatr Int 2015;57:1143-8. 